\title{
Systematic review and meta-analysis on bipolar versus monopolar transurethral resection of bladder tumors
}

\author{
Wojciech Krajewski ${ }^{1} \wedge$, Łukasz Nowak ${ }^{1}$, Marco Moschini ${ }^{2}$, Andrea Mari $^{3}$, Ettore Di Trapani ${ }^{4}$, \\ Evanguelos Xylinas ${ }^{5}$, Andrzej Tukiendorf ${ }^{6}$, Sławomir Poletajew ${ }^{7}$, Romuald Zdrojowy ${ }^{1}$; on behalf of Young \\ Academic Urologists (YAU), Urothelial Cancer Party
}

${ }^{1}$ Department of Urology and Urological Oncology, Wroclaw Medical University, Wroclaw, Poland; ${ }^{2}$ Klinik für Urologie, Luzerner Kantonsspital, Lucerne, Switzerland; ${ }^{3}$ Unit of Oncologic Minimally-Invasive Urology and Andrology, Department of Urology, Careggi Hospital, University of Florence, Florence, Italy; ${ }^{4}$ Department of Urology and Division of Experimental Oncology, URI, Urological Research Institute, IRCCS San Raffaele Scientific Institute, Milan, Italy; ${ }^{5}$ Department of Urology, Bichat-Claude Bernard Hospital, Assistance Publique-Hôpitaux de Paris, Paris Descartes University, Paris, France; ${ }^{6}$ Department of Public Health, Wrocław Medical University, Wrocław, Poland; ${ }^{7}$ Second Department of Urology, Medical Centre of Postgraduate Education, Warsaw, Poland

Contributions: (I) Conception and design: W Krajewski, M Moschini, E Xylinas; (II) Administrative support: A Mari, E Di Trapani; (III) Provision of study materials or patients: A Mari, E Di Trapani; (IV) Collection and assembly of data: W Krajewski, Ł Nowak; (V) Data analysis and interpretation: W Krajewski, Ł Nowak; (VI) Manuscript writing: All authors; (VII) Final approval of manuscript: All authors.

Correspondence to: Wojciech Krajewski. Department of Urology and Oncological Urology, Wroclaw Medical University, Borowska 213, Wroclaw, Poland. Email: wk@softstar.pl.

Background: Transurethral resection of bladder tumour (TURB) is the initial and crucial step in the management of non-muscle invasive bladder cancer (NMIBC), having both diagnostic and therapeutic role. For many years, the gold standard for TURB was monopolar TURB (mTURB), however, it is associated with several complications related to its technical details. To overcome limitations of mTURB, TURB using bipolar technology (bTURB) has been developed. So far, making unequivocal statement about definitive advantage of bTURB over mTURB was difficult. The aim of this study was to systematically evaluate and compare the efficacy and safety of bTURB with mTURB.

Methods: A systematic search was conducted independently by two authors on the 4 electronic databases, including PubMed, Scopus, Embase and Cochrane Library, according to Preferred Reporting Items for Systematic Reviews and Meta-Analysis (PRISMA) statement. Nine comparative prospective studies with randomization (8 RCTs and 1 post-hoc analysis of RCT) were eligible to be included in this meta-analysis

Results: After extraction, data were pooled to conduct the meta-analysis. The following outcomes were analysed: operation time, catheterization time, length of hospital stay, decrease in postoperative haemoglobin level, obturator nerve reflex rate, bladder perforation rate, transfusion rate, TUR syndrome rate, one year recurrence rate, failures of detrusor muscle detection. bTURB was associated with decreased operation and hospitalization time. There were no statistically significant differences between bTURB and mTURB in terms of catheterization time, decrease in haemoglobin level, postoperative complications rates, recurrence rates and pathologic outcomes.

Conclusions: This meta-analysis corroborates that bTURB shows significant advantage over mTURB in terms of operation and hospitalization time while other outcomes are comparable.

Keywords: Bladder cancer (BC); transurethral resection of bladder tumour (TURB); monopolar; bipolar

Submitted Mar 11, 2020. Accepted for publication Aug 19, 2020.

doi: $10.21037 /$ tau-20-749

View this article at: http://dx.doi.org/10.21037/tau-20-749

$\wedge$ ORCID: 0000-0003-1727-2283. 


\section{Introduction}

Bladder cancer (BC) is one of the most commonly diagnosed malignancies worldwide. Every year it affects almost 430,000 people and it positions $13^{\text {th }}$ in terms of yearly oncological mortality. Furthermore, the incidence of $\mathrm{BC}$ is constantly increasing (1). It is estimated that $75 \%$ of primary diagnosed BCs present as non-muscle invasive cancers (NMIBC) (2). Transurethral resection of bladder tumour (TURB) is the initial and crucial step in the management of NMIBC, having both diagnostic and therapeutic role. The particular aim of this procedure is to establish the proper histological diagnosis and important prognostic factors as well as achieve a complete removal of tumour $(2,3)$. The gold standard for TURB is conventional TURB (cTURB), classically performed with monopolar current (mTURB). However, mTURB is associated with several complications related to its technical details, e.g., serum electrolytes concentrations disturbances possibly resulting in TUR syndrome, risk of obturator nerve reflex possibly resulting in bladder perforation or thermal damage of resection chips hindering the histopathological assessment (3-5). To overcome limitations of mTURB, TURB using bipolar technology (bTURB) has been developed $(6,7)$.

So far, making unequivocal statement about definitive advantage of bTURB over mTURB was difficult. As several randomized controlled trials (RCTs) have been published in recent years, we decided to conduct a systematic review and meta-analysis, comparing safety and efficacy of bTURB and mTURB. Our main goal was to investigate whether bTURB and mTURB differ significantly in terms of perioperative outcomes and postoperative complications rates.

We present the following article in accordance with the PRISMA reporting checklist (available at http://dx.doi. org/10.21037/tau-20-749).

\section{Methods}

\section{Search strategy}

A systematic search was conducted independently by two authors (WK and LN) through the 4 electronic databases, including PubMed, Scopus, Embase and Cochrane Library, according to Preferred Reporting Items for Systematic Reviews and Meta-Analysis (PRISMA) statement (8). Additionally, resource centres from biggest urological conferences were searched. Last search was performed on $10^{\text {th }}$ February. The Medical Subject Heading (MeSH) terms and/or key words and/or free words were: bladder cancer, TURB, bipolar, monopolar OR conventional. Boolean operators (NOT, AND, OR) were used in succession to narrow and broaden the search. The search included articles without time limitations. Only publications in English were considered and evidence was limited to human data.

\section{Inclusion and exclusion criteria}

In this meta-analysis studies which met the following criteria were included: (I) study including any form of randomization; (II) study including patients diagnosed with suspected NMIBC; (III) study comparing bladder tumour resection performed with monopolar and bipolar electric energy. Retrospective and nonrandomized articles were excluded as well as review articles, case reports, letters, commentaries or observational studies. Also, studies including comparison of other operative methods than TURB (e.g., bipolar plasma vaporisation) and those with incomplete data about measured features were additionally excluded.

\section{Data extraction and quality assessment}

Two authors (WK and LN) independently evaluated the search strategy results using prespecified eligibility criteria, and exclusions were documented systematically. Disagreements were resolved by consultation with other authors. The following data were initially extracted: first author, year of publication, country, study design, number of patients in bTURB and mTURB groups, inclusion and exclusion criteria of particular studies, participant demographics and baseline tumour characteristics. Further, following outcomes were retrieved: (I) perioperative outcomes (operation time, length of hospital stay, catheterization time, decrease in postoperative haemoglobin (Hb) level; (II) postoperative complication rates (obturator nerve reflex, bladder perforation, blood loss requiring transfusion, TUR syndrome); (III) one year recurrence rates; (IV) pathologic outcomes (absence of detrusor muscle). For articles that lacked some data authors were contacted to deliver information from their research, yet, no additional data was received.

For all included studies in this meta-analysis level of evidence (LoE) was independently estimated according to the criteria provided by the Oxford Centre for Evidence Based Medicine (9). 


\section{Risk of bias assessment}

The risk of bias in included studies was assessed using Revised Cochrane's Risk of Bias 2 Tool (RoB 2 Tool) (10). This included assessment of bias arising from: randomization process, deviations from intended interventions, missing outcomes data, measurement of the outcomes, selection of the reported results. Two authors (WK and RZ) independently applied the RoB 2 Tool and resolved disagreements by discussion with other authors. Additionally, funnel plots were used to assess the publication bias of included studies. Because the visual interpretation of funnel plot asymmetry is inherently subjective, we also formally tested funnel plot asymmetry using the Egger test (11).

\section{Statistical analysis}

After extraction, data were pooled to conduct the metaanalysis. Review Manager (RevMan) Version 5.3 was the software used (The Cochrane Collaboration, The Nordic Cochrane Centre, Copenhagen, 2014). Outcomes for dichotomous variables were expressed as odds ratio (OR) with $95 \%$ confidence intervals (95\% CI). The MantelHaenszel (M-H) method was used for the combination of this result. In the case of continuous variables, pooled results were calculated using the weighted mean difference (WMD) with 95\% CI. These results were combined using the inverse variance (IV) method. If the study did not provide the standard deviation (SD), we calculated it based on the approximate transformation from available ranges (12). Variations among the studies were evaluated with the use of the chi-square test. Also, heterogeneity $\mathrm{I}^{2}$ index was calculated in order to indicate the proportion of inconsistency between studies that could not be attributed to chance. When $\mathrm{I}^{2}<50 \%$, the evidences showed no significant heterogeneity, therefore we used the fixed-effect (FE) model. Otherwise, random-effect (RE) model was applied. Potential sources of heterogeneity, if significant, were explored using sensitivity analysis, performed by omitting a certain study each time. For all tests, $\mathrm{P}<0.05$ was considered a statistically significant difference.

\section{Results}

\section{Workflow of literature search}

After screening 263 publications, nine comparative prospective studies with randomization (8 RCTs and 1 posthoc analysis of RCT) were eligible to be included in this meta-analysis (13-21). Figure 1 shows the selection process of the study.

\section{Study identification and quality assessment}

Included studies recruited overall 1,723 participants. In 911 cases patients had bTURB and in 812 mTURB (Table 1). There was no statistical difference and heterogeneity between bTURB and mTURB group populations in terms of age, gender, tumour stage and tumour focality. The populations analysed in this paper were not utterly comparable in terms of tumour size and tumour location. Two trials reported only patients with tumour $>3 \mathrm{~cm}(16,18)$, one trial reported only tumours located on lateral bladder wall (15), and one only patients with coronary artery disease (CAD) (13). Eligibility criteria, exclusion criteria and basic tumour characteristic of particular trials are presented in Table 2.

For all included studies LoE was $2 \mathrm{~b}$, which was considered appropriate for this meta-analysis (Table 1).

\section{Risk of bias assessment}

The results of the RoB assessment (overall and stratified by RoB 2 Tool domains) are presented in Figure 2. One trial had overall low RoB, 6 trials had a moderate RoB and 2 trials had high overall RoB. In addition, publication bias was evaluated by funnel plot symmetry analysis as well as Egger test and no obvious biases were identified (data not shown).

\section{Perioperative results}

Operation time was available for 9 trials and there was no significant difference in study heterogeneity $(\mathrm{P}=0.28$; $\mathrm{I}^{2}=18 \%$ ). The pooled WMD was -2.56 (FE model: $95 \%$ $\mathrm{CI}=-3.62$ to $-1.51 ; \mathrm{P}<0.001)$, indicating that operation time was significantly shorter in bTURB group (Figure $3 A$ ). bTURB was also associated with shorter hospitalization time, reported in 5 trials (RE model: $M D=-0.46 ; 95 \%$ CI $=-0.89$ to $-0.03 ; \mathrm{P}=0.04$ ) (Figure $3 B$ ). Catheterization time was available for 3 trials. The pooled WMD was -0.33 (RE model: $95 \% \mathrm{CI}=-1.16$ to $0.49 ; \mathrm{P}=0.43)$, indicating that there was no significant difference between bTURB and mTURB group (Figure 3C). bTURB was also not associated with significant decrease in postoperative $\mathrm{Hb}$ level (RE model; WMD $=-0.21 ; 95 \% \mathrm{CI}=-0.52$ to $0.09 ; \mathrm{P}=0.17$ ) (Figure $3 D$ ). Analysis revealed a significant heterogeneity for hospitalization time $\left(\mathrm{P}<0.001 ; \mathrm{I}^{2}=90 \%\right)$, catheterization 


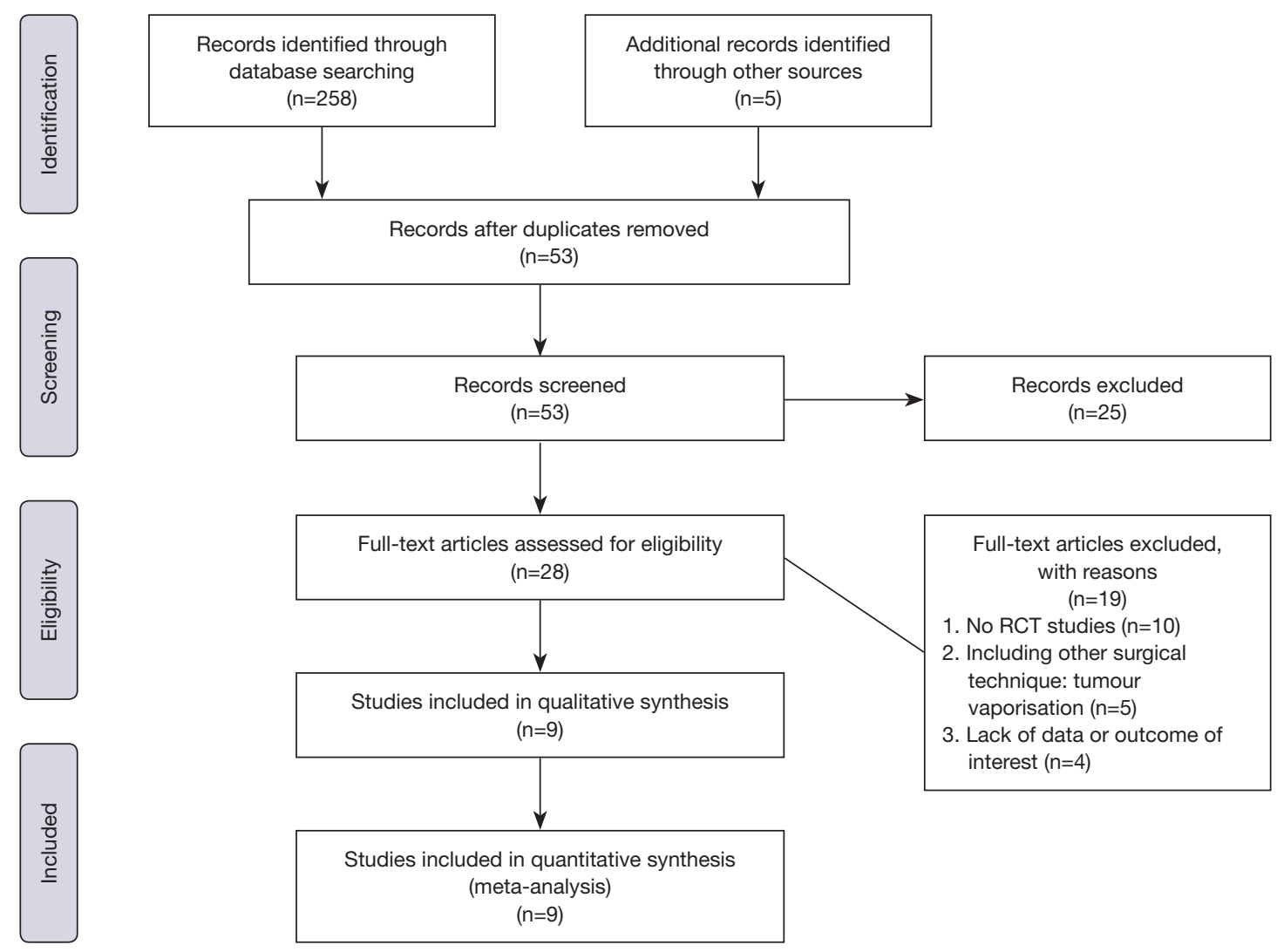

Figure 1 Flow diagram of meta-analysis.

Table 1 Baseline characteristic of the included studies

\begin{tabular}{|c|c|c|c|c|c|c|c|}
\hline First author & Year & Country & Design & \multicolumn{2}{|c|}{ No. of patients } & $\begin{array}{l}\text { Matching } \\
\text { variables* }^{*}\end{array}$ & $\begin{array}{l}\text { Level of } \\
\text { evidence }^{\star \star}\end{array}$ \\
\hline Bolat (13) & 2018 & Turkey & $\mathrm{RCT}$ & 48 & 42 & $1.2,3,4,5$ & $2 b$ \\
\hline Del Rosso (14) & 2013 & Italy & $\mathrm{RCT}$ & 67 & 65 & $1,2,4,5$ & $2 b$ \\
\hline Gramann (15) & 2018 & Switzerland & RCT & 23 & 21 & $1,2,3,4,6$ & $2 b$ \\
\hline Liem (17) & 2018 & $\begin{array}{c}\text { The } \\
\text { Netherlands }\end{array}$ & $\begin{array}{c}\text { Post-hoc } \\
\text { analysis of RCT }\end{array}$ & 406 & 310 & $\begin{array}{c}1,2,3,4 \\
5,6\end{array}$ & $2 b$ \\
\hline Mahmoud (18) & 2019 & Egypt & $\mathrm{RCT}$ & 40 & 40 & $\begin{array}{c}1,2,3,4 \\
5,6\end{array}$ & $2 b$ \\
\hline Murugavaithianathan (19) & 2018 & India & $\mathrm{RCT}$ & 80 & 80 & $\begin{array}{c}1,2,3,4 \\
5,6\end{array}$ & $2 b$ \\
\hline Venkatramani (21) & 2014 & India & RCT & 72 & 75 & $\begin{array}{c}1,2,3,4 \\
5,6\end{array}$ & $2 b$ \\
\hline
\end{tabular}

*: 1, age; 2, gender; 3, tumour size; 4, tumour stage; 5 , tumour focality; 6 , tumour localization. ${ }^{* \star}$, based on criteria provided by Oxford Centre for Evidence Based Medicine. \#, first author's country, study is multicenter. bTURB, bipolar transurethral resection of bladder tumour; mTURB, monopolar transurethral resection of bladder tumour; RCT, randomized controlled trial. 
Table 2 Eligibility criteria, exclusion criteria and tumour characteristic of particular trials

\begin{tabular}{|c|c|c|c|c|c|c|c|c|}
\hline \multirow{2}{*}{ First author, year, journal } & \multirow{2}{*}{ Eligibility criteria } & \multirow{2}{*}{ Exclusion criteria } & \multicolumn{2}{|c|}{ Tumour size, mean (cm) } & \multicolumn{2}{|c|}{ Tumour focality (n) } & \multicolumn{2}{|c|}{ Final tumour stage $(n)$} \\
\hline & & & bTURB & mTURB & bTURB & mTURB & bTURB & mTURB \\
\hline $\begin{array}{l}\text { Bolat, } 2018 \text { International } \\
\text { Brazil Journal of Urology }\end{array}$ & $\begin{array}{l}\text { Patients: who underwent TURB for } \\
\text { overt or suspected bladder cancers on } \\
\text { radiological imagings and/or cystoscopy; } \\
\text { who had grade } 2 \text { or } 3 \text { coronary artery } \\
\text { disease (CAD) according to New York } \\
\text { Heart Association's (NYHA) classification }\end{array}$ & $\begin{array}{l}\text { Patients without coronary artery disease } \\
\text { (CAD); acute UTI; absence of urothelial } \\
\text { cancer on pathology report after TURB; } \\
\text { TURB for residual tumours; re-staging or } \\
\text { recurrent bladder tumours; patients who } \\
\text { were not suitable for spinal anesthesia }\end{array}$ & 3 & 3.1 & $2.0 \pm 1.6$ (mean number) & $1.8 \pm 1.4$ (mean number) & Ta: 22; T1: 15; CIS: 1; T2:11 & Ta: 24; T1: 12; CIS: 1; T2: 6 \\
\hline $\begin{array}{l}\text { Del Rosso, } 2013 \text { International } \\
\text { Journal of Urology }\end{array}$ & $\begin{array}{l}\text { All patients planned for TURB with a new } \\
\text { diagnosis of bladder tumour irrespective } \\
\text { of size, site and multiplicity }\end{array}$ & $\begin{array}{l}\text { Patients with UTI and who reported a } \\
\text { MIBC after TURB }\end{array}$ & NR & NR & Single/multiple 56/11 & Single/multiple 54/11 & Ta: 49; T1: 18 & Ta: 47; T1: 18 \\
\hline $\begin{array}{l}\text { Gramann, } 2018 \text { World Journal } \\
\text { of Urology }\end{array}$ & $\begin{array}{l}\text { Tumour on the lateral bladder wall } \\
\text { (lateral to ureteral orifice); elective TURB; } \\
\text { operability; written informed consent }\end{array}$ & $\begin{array}{l}\text { UTI; pregnancy; age < } 18 \text { years or lack of } \\
\text { legal majority; antiplatelet agents (except } \\
\text { ASA } \leq 100 \mathrm{mg} \text { ) }\end{array}$ & $<1 \mathrm{~cm}: 12 ;>1 \mathrm{cm:} 11$ & $<1 \mathrm{~cm}: 5 ;>1 \mathrm{cm:} 16$ & NR & NR & $\begin{array}{c}\text { No tumour: 2; Ta: } 16 ; \text { T1: } 3 ; \\
\text { T2: } 2\end{array}$ & $\begin{array}{l}\text { No tumour: 2; Ta: 13; T1:3; } \\
\text { T2: } 3\end{array}$ \\
\hline $\begin{array}{l}\text { Hashad, } 2018 \text { Arab Journal of } \\
\text { Urology }\end{array}$ & $\begin{array}{l}\text { Patients: presenting with bladder } \\
\text { tumours of }>3 \mathrm{~cm} \text { in maximum diameter; } \\
\text { receiving low-dose aspirin }(81 \mathrm{mg} / \text { day) } \\
\text { as antiplatelet therapy, which was not } \\
\text { stopped before surgery }\end{array}$ & $\begin{array}{l}\text { Patients with recurrent tumours and } \\
\text { patients with CT or MRI evidence of } \\
\text { MIBC }\end{array}$ & 3.46 & 3.5 & Single/multiple 70/30 & Single/multiple 68/32 & NR & NR \\
\hline $\begin{array}{l}\text { Liem, } 2018 \text { Urologic } \\
\text { Oncology: Seminars and } \\
\text { Original Investigations }\end{array}$ & $\begin{array}{l}\text { Patients with primary NMIBC treated } \\
\text { with mTURB or bTURB }\end{array}$ & $\begin{array}{l}\text { Tumours other than NMIBC; unknown } \\
\text { resection technique }\end{array}$ & 2.08 & 2.08 & Single/multiple 221/182 & Single/multiple 187/123 & Ta: 258; T1: 137; CIS: 11 & Ta: 153; T1: 150; CIS: 7 \\
\hline $\begin{array}{l}\text { Mahmoud, } 2019 \text { Arab Journal } \\
\text { of Urology }\end{array}$ & $\begin{array}{l}\text { Patients with newly diagnosed } \\
\text { primary bladder tumours, with tumour } \\
\text { size }>3 \mathrm{~cm}\end{array}$ & $\begin{array}{l}\text { Patients: not suitable for spinal } \\
\text { anaesthesia; with recurrent bladder } \\
\text { tumours; with other urological } \\
\text { malignancies; requiring anticoagulation; } \\
\text { with pacemakers; with back pressure } \\
\text { change, with urethral stricture; with } \\
\text { active UTIs; with uncontrolled bleeding } \\
\text { diathesis }\end{array}$ & 4.09 & 4.06 & Single/multiple 35/5 & Single/multiple 33/7 & Ta: 12; T1: 22; T2: 6 & Ta: 8; T1: 22; T2: 10 \\
\hline $\begin{array}{l}\text { Murugavaithianathan 2018, } \\
\text { Journal of Endourology }\end{array}$ & $\begin{array}{l}\text { Patients with bladder tumour undergoing } \\
\text { TURB under regional anesthesia }\end{array}$ & $\begin{array}{l}\text { Patients: undergoing re-TURB; requiring } \\
\text { general anaesthesia; who refused to give } \\
\text { informed consent }\end{array}$ & 2.7 & 2.5 & Single/multiple 65/15 & Single/multiple 70/10 & Ta: 19; T1: 35; T2: 15 & Ta: 13; T1: 44; T2: 18 \\
\hline $\begin{array}{l}\text { Teoh, } 2016 \text { Annals of Surgical } \\
\text { Oncology }\end{array}$ & $\begin{array}{l}\text { All patients who were diagnosed by } \\
\text { cystoscopy to have a bladder tumour } \\
\text { (either primary or recurrent) and who } \\
\text { were planned for TURB }\end{array}$ & $\begin{array}{l}\text { Patients who had prior TURB performed } \\
\text { within a 6-week period }\end{array}$ & 2.34 & 2.21 & Single/multiple $45 / 30$ & Single/multiple $45 / 34$ & Ta: 43; T1: 13; T2: 9 & Ta: 33; T1: 22; T2: 7 \\
\hline $\begin{array}{l}\text { Venkatramani, } 2014 \text { Journal } \\
\text { of Urology }\end{array}$ & $\begin{array}{l}\text { All consecutive patients undergoing } \\
\text { TURB for suspected bladder tumours }\end{array}$ & $\begin{array}{l}\text { Restaging TURB for high grade bladder } \\
\text { cancer; refusal to participate; unfitness } \\
\text { for spinal anesthesia }\end{array}$ & 4.38 & 4.55 & 2.51 (mean number) & 1.97 (mean number) & $\begin{array}{l}\text { Ta: 21; T1:26; T2: 17; CIS: } \\
\text { 1; Misc: } 7\end{array}$ & $\begin{array}{l}\text { Ta: 22; T1: 23; T2: 21; CIS: } \\
\text { 0; Misc: } 9\end{array}$ \\
\hline
\end{tabular}

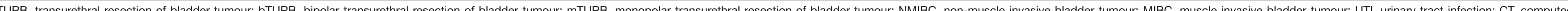
tomography; MRI, magnetic resonance imaging; NR, not reported. 

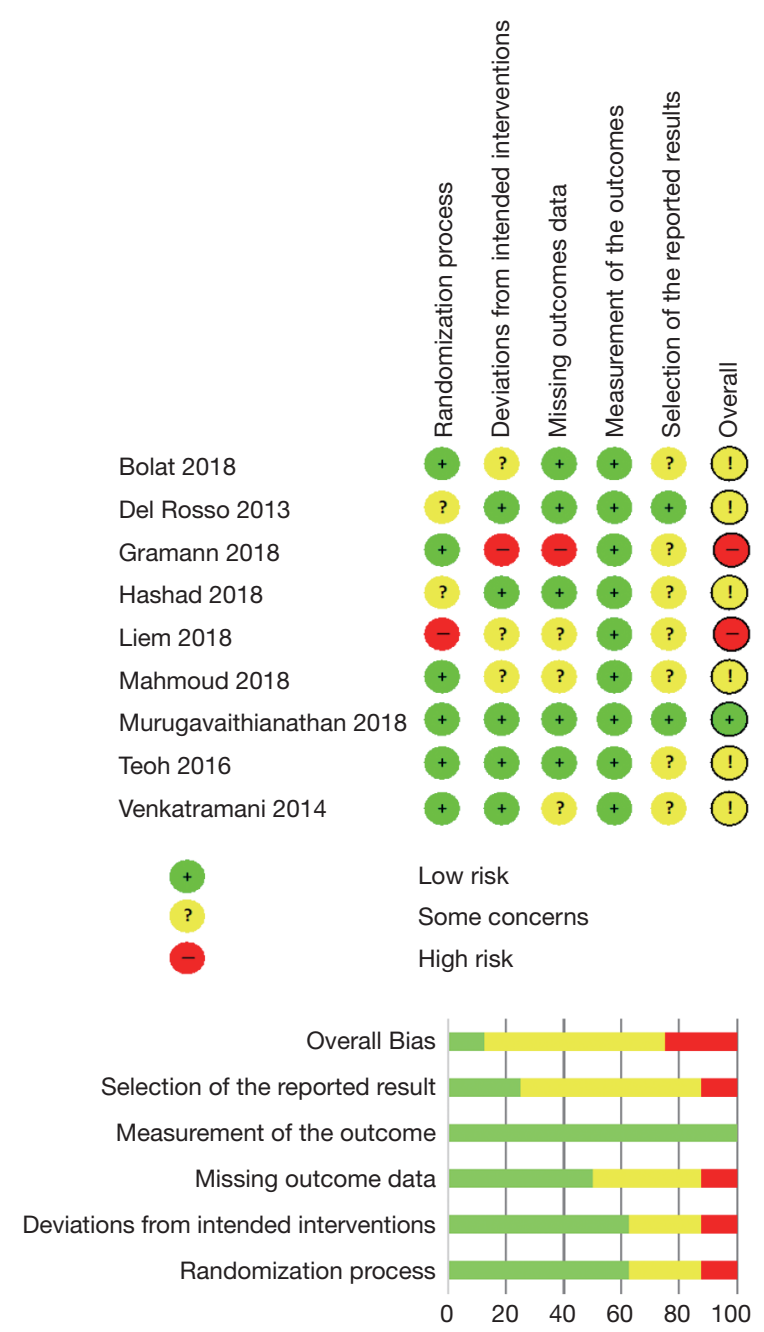

Figure 2 Risk of bias assessment.

time $\left(\mathrm{P}<0.001 ; \mathrm{I}^{2}=91 \%\right)$ and postoperative $\mathrm{Hb}$ level decrease $\left(\mathrm{P}<0.001 ; \mathrm{I}^{2}=95 \%\right)$, thus, a $\mathrm{RE}$ model was applied, and further discussion was made to explain the heterogeneity.

\section{Complications}

All 9 trials reported obturator nerve reflex rate. Heterogeneity was not detected among the trials $(\mathrm{P}=0.08$, $\left.\mathrm{I}^{2}=43 \%\right)$. There was no statistically significant difference in obturator nerve reflex rate between bTURB and mTURB group (FE model: $\mathrm{OR}=0.81 ; 95 \% \mathrm{CI}=0.60$ to 1.09; $\mathrm{P}=0.16$ ) (Figure $4 A$ ). Pooled analysis revealed also no significant difference between bTURB and mTURB on bladder perforation (FE model: $\mathrm{OR}=0.81 ; 95 \% \mathrm{CI}=0.49$ to $1.35 ; \mathrm{P}=0.42)$ (Figure $4 B$ ). Heterogeneity was not detected among the studies $\left(\mathrm{P}=0.30 ; \mathrm{I}^{2}=16 \%\right)$. In 1 trial (20) either in bTURB or mTURB group number of bladder perforations was 0 , thus the OR was not estimable. All trials reported data on transfusion rates and statistical heterogeneity among them was not detected $\left(\mathrm{P}=0.15 ; \mathrm{I}^{2}=44 \%\right)$. Pooled analysis revealed no differences between bTURB and mTURB group on postoperative transfusion rates (FE model: OR $=1.29 ; 95 \% \mathrm{CI}=0.49$ to $3.44 ; \mathrm{P}=0.61$ ) (Figure $4 C$ ). In 5 trials $(14,15,18-20)$ either in bTURB or mTURB group number of blood transfusions was 0 , so the OR was not estimable. Overall, only 3 cases of TUR syndrome were reported in included studies $(18,21)$, all among patients in mTURB group. Meta-analysis on this complication could not be reliably performed due to small sample size.

\section{One year recurrence rate}

Follow-up data of 1 year recurrence rates were provided by 3 trials. Analysis showed that there was no significant difference in 1 year recurrence rate between bTURB and mTURB group. The pooled OR was 0.85 (FE model: $95 \%$ $\mathrm{CI}=0.63$ to $1.15 ; \mathrm{P}=0.29)$ and statistical heterogeneity among the trials was not detected $\left(\mathrm{P}=0.76 ; \mathrm{I}^{2}=0 \%\right)$ (Figure 5).

\section{Pathological outcomes}

Because of the different evaluation measures of thermal damage of specimens after TURB in each study, metaanalysis could not be performed. However, 5 trials reported data of detrusor muscle presence after bTURB and mTURB procedures. Analysis of failures in detrusor muscle detection from collected specimens was performed and pooled analysis revealed no differences between bTURB and mTURB (FE model: $\mathrm{OR}=0.83 ; 95 \% \mathrm{CI}=0.55$ to 1.26 ; $\mathrm{P}=0.39 ; \mathrm{I}^{2}=0 \%$ ) (Figure 6).

\section{Sensitivity analysis}

A sensitivity analysis was performed by deleting one study each time to assess the influence of an individual study on synthetic statistics. The results showed when the study of Del Rosso (14) or Hashad (16) was omitted, the result of hospitalization time demonstrated no significant statistical difference (Del Rosso: $\mathrm{MD}=-0.23 ; 95 \% \mathrm{CI}=-0.53$ to $0.07 ; \mathrm{P}=0.13$; Hashad: $\mathrm{MD}=-0.46 ; 95 \% \mathrm{CI}=-1.16$ to $0.25 ; \mathrm{P}=0.20)$. Also, when the study of Venkatramani (21) was omitted, the result of obturator nerve reflex rate 


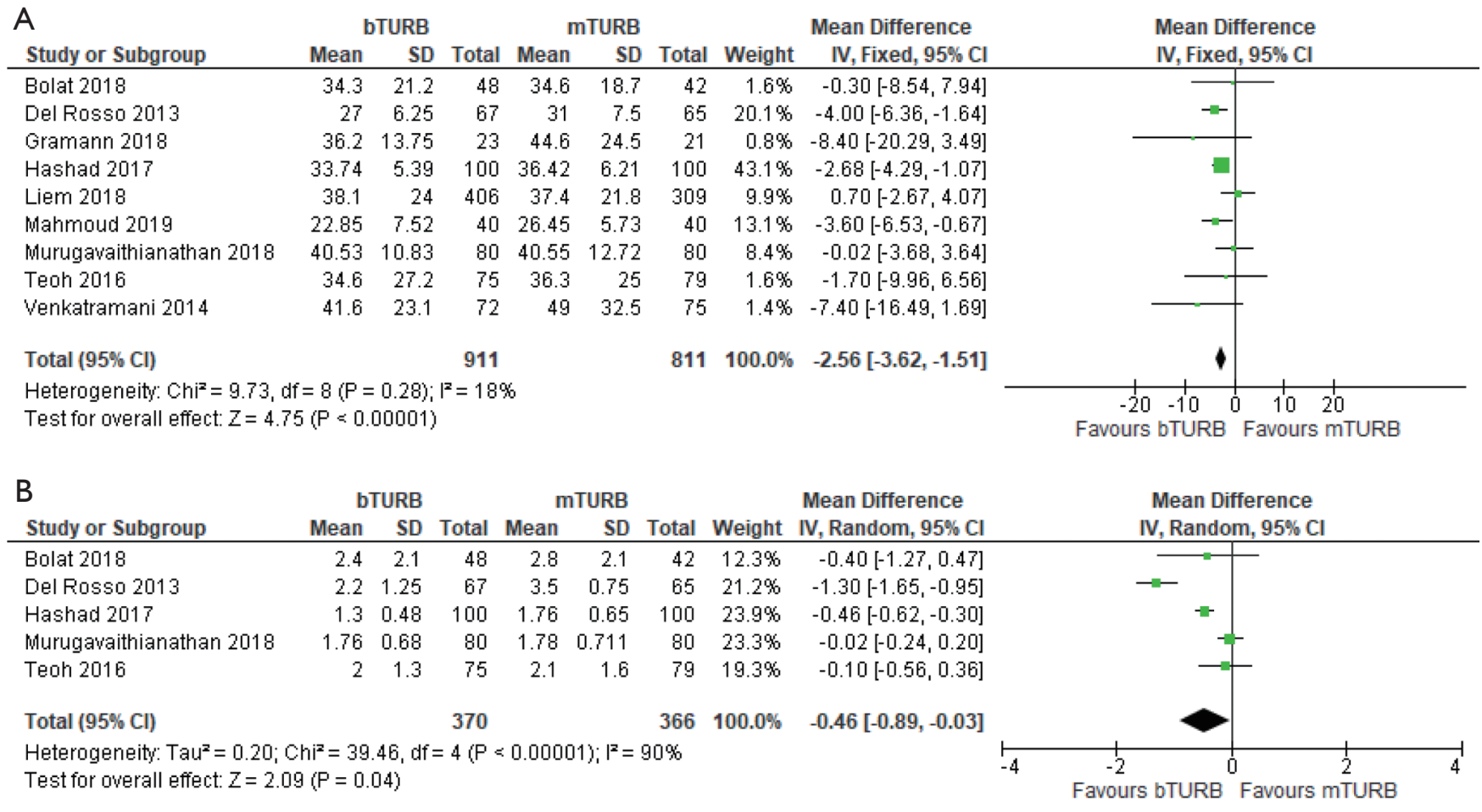

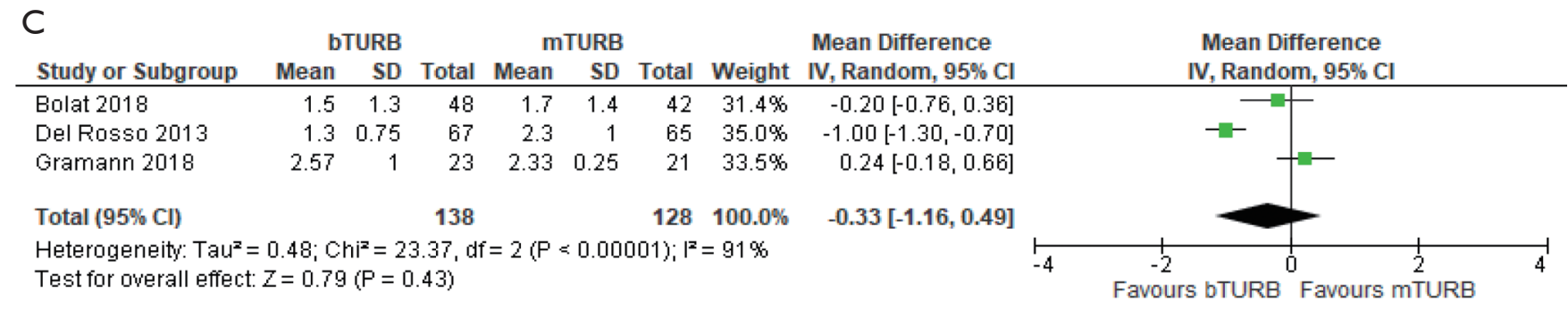

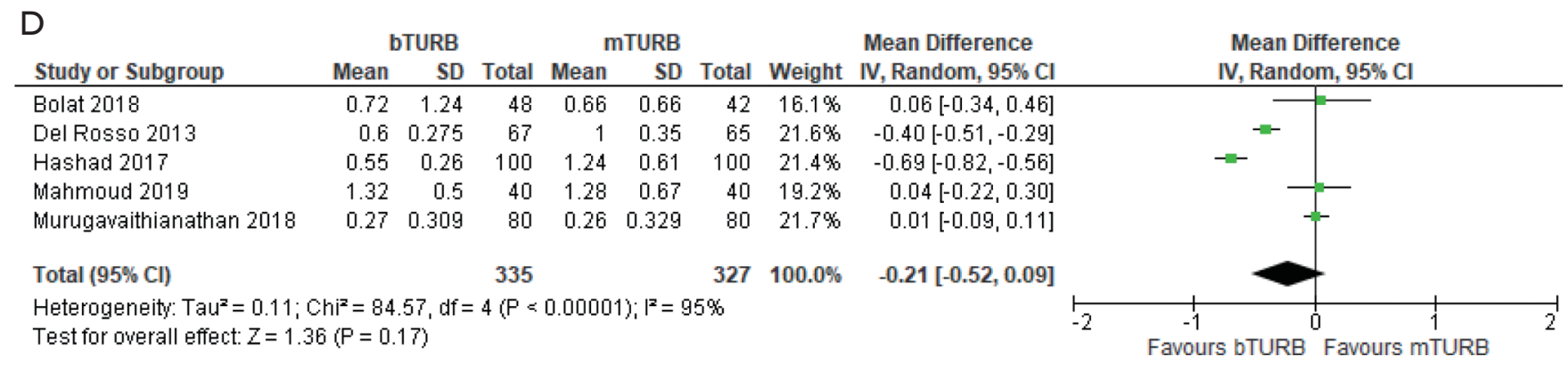

Figure 3 Forest plots and meta-analyses of perioperative outcomes: (A) operation time (min); (B) hospitalization time (days); (C) catheterization time (days); (D) decrease in postoperative $\mathrm{Hb}$ level $(\mathrm{g} / \mathrm{dL})$. bTURB, bipolar transurethral resection of bladder tumour; mTURB, monopolar transurethral resection of bladder tumour; 95\% CI, 95\% confidence interval; SD, standard deviation; IV, inverse variance.

demonstrated significant difference between bTURB and mTURB group $(\mathrm{OR}=0.71 ; 95 \% \mathrm{CI}=0.51$ to $0.99 ; \mathrm{P}=0.04)$. No other change of significance of the pooled comparison between the two groups was influenced by removing any single study, indicating that the results of our meta-analysis were stable. 


\begin{tabular}{|c|c|c|c|c|c|c|c|c|c|c|}
\hline \multirow[b]{2}{*}{ Study or Subgroup } & \multicolumn{2}{|c|}{ bTURB } & \multicolumn{2}{|c|}{ mTURB } & \multirow[b]{2}{*}{ Weight } & \multirow{2}{*}{$\begin{array}{c}\text { Odds Ratio } \\
\text { M-H, Fixed, } 95 \% \mathrm{Cl}\end{array}$} & \multirow{2}{*}{\multicolumn{4}{|c|}{$\begin{array}{c}\text { Odds Ratio } \\
\text { M-H, Fixed, } 95 \% \mathrm{Cl}\end{array}$}} \\
\hline & Events & Total & Events & Total & & & & & & \\
\hline Bolat 2018 & 1 & 48 & 7 & 42 & $7.6 \%$ & $0.11[0.01,0.90]$ & & & & \\
\hline Del Rosso 2013 & 1 & 67 & 1 & 65 & $1.0 \%$ & $0.97[0.06,15.84]$ & & & & \\
\hline Gramann 2018 & 4 & 23 & 8 & 21 & $7.2 \%$ & $0.34[0.09,1.38]$ & & & & \\
\hline Hashad 2017 & 12 & 100 & 15 & 100 & $13.7 \%$ & $0.77[0.34,1.75]$ & & & $\leftarrow$ & \\
\hline Liem 2018 & 25 & 406 & 22 & 309 & $24.3 \%$ & $0.86[0.47,1.55]$ & & - & & \\
\hline Wahmoud 2019 & 2 & 40 & 10 & 40 & $9.8 \%$ & $0.16[0.03,0.78]$ & & & & \\
\hline Murugavaithianathan 2018 & 13 & 80 & 8 & 80 & $6.9 \%$ & $1.75[0.68,4.48]$ & & & & \\
\hline Teoh 2016 & 12 & 75 & 16 & 79 & $13.6 \%$ & $0.75[0.33,1.71]$ & & & & \\
\hline Venkatramani 2014 & 33 & 72 & 29 & 75 & $15.9 \%$ & $1.34[0.70,2.59]$ & & & & \\
\hline Total $(95 \% \mathrm{Cl})$ & & 911 & & 811 & $100.0 \%$ & $0.81[0.60,1.09]$ & & & & \\
\hline Total events & 103 & & 116 & & & & & & & \\
\hline $\begin{array}{l}\text { Heterogeneity: Chi }=13.91 \\
\text { Test for overall effect: } Z=1 .\end{array}$ & $\begin{array}{l}d f=8(P= \\
0(P=0.1\end{array}$ & $=0.08) ;$ & $F^{2}=43 \%$ & & & & 0.01 & $\begin{array}{c}0.1 \\
\text { Favours bTURB }\end{array}$ & $\begin{array}{cc}10 \\
\text { Favours mTURB }\end{array}$ & 100 \\
\hline
\end{tabular}

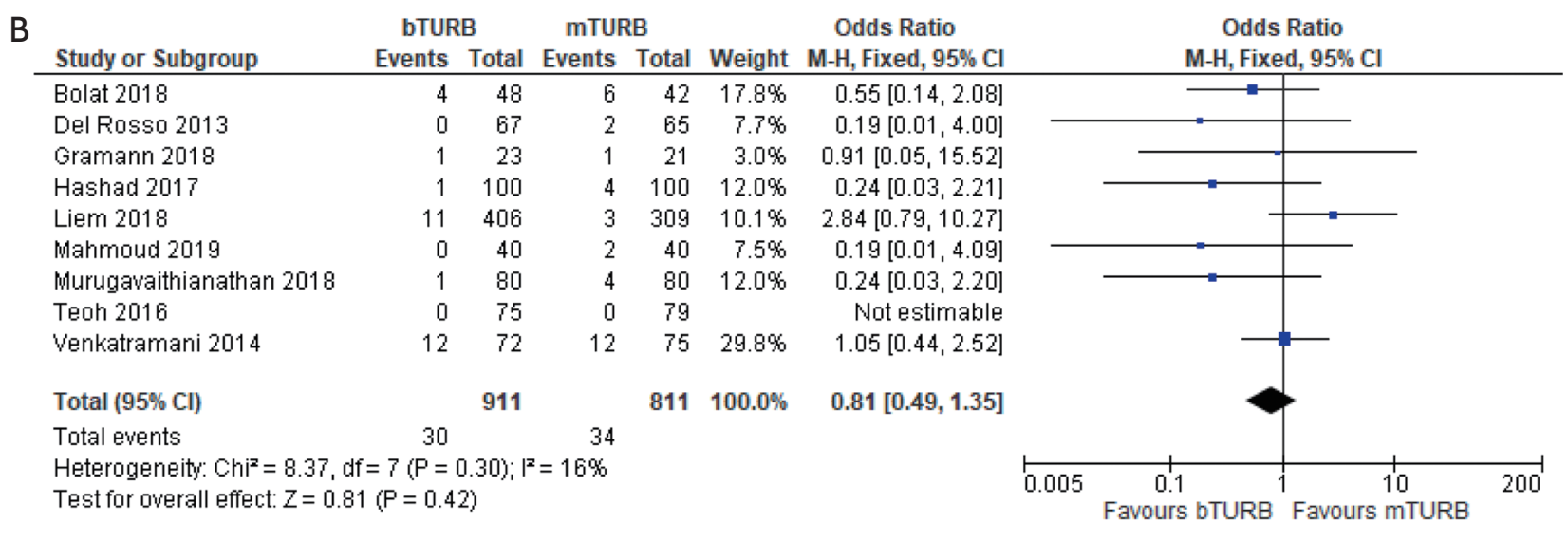

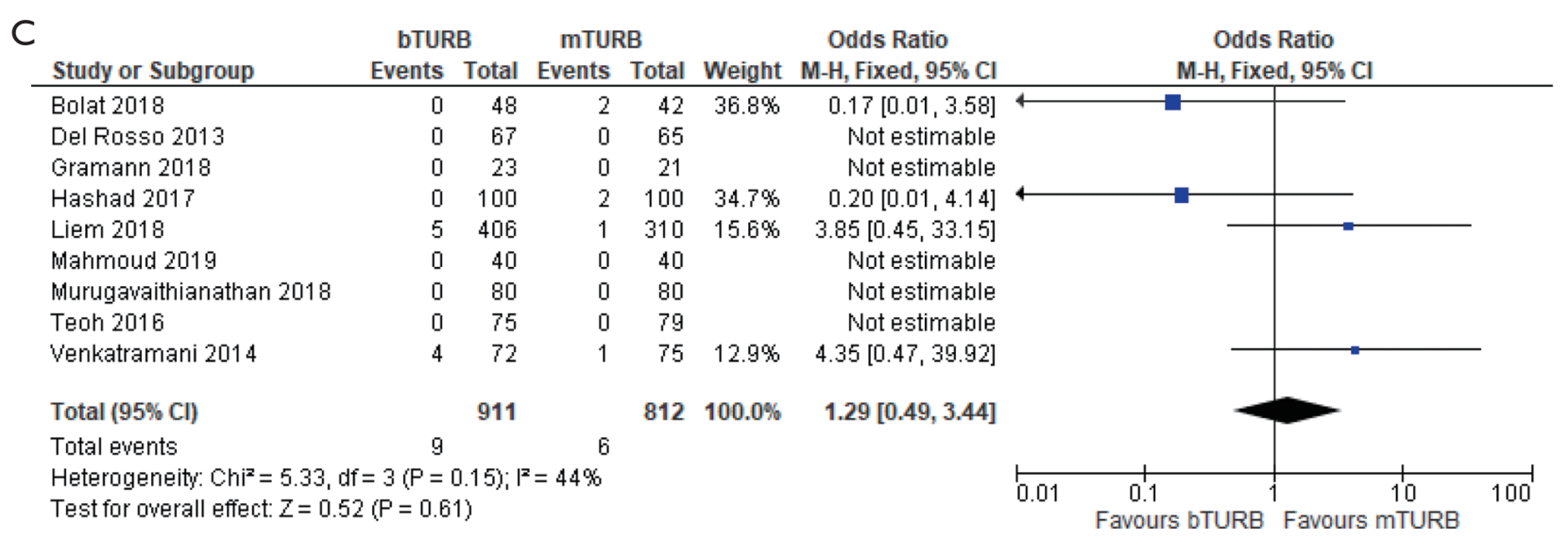

Figure 4 Forest plots and meta-analyses of complication rates: (A) obturator nerve reflex; (B) bladder perforation; (C) blood loss requiring transfusion. bTURB, bipolar transurethral resection of bladder tumour; mTURB, monopolar transurethral resection of bladder tumour; 95\% CI, 95\% confidence interval; M-H, Mantel-Haenszel method.

\section{Discussion}

Correctly managed NMIBCs present relatively good survival rates. Nevertheless, the risk of tumour recurrence or progression to muscle invasive disease is very high $(22,23)$.
Therefore, to ensure good diagnostic and therapeutic quality, TURB is a subject of continuous technological development $(2,3,24)$. Originally, TURB was performed with monopolar electrocautery. The technique has been 


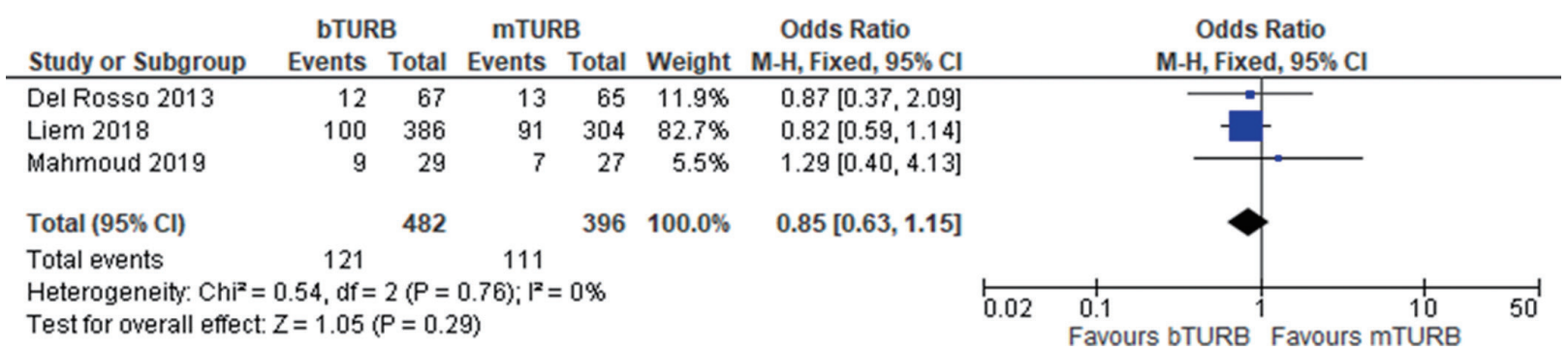

Figure 5 Forest plot and meta-analysis of one-year recurrence rate bTURB, bipolar transurethral resection of bladder tumour; mTURB, monopolar transurethral resection of bladder tumour; 95\% CI, 95\% confidence interval; M-H, Mantel-Haenszel method.

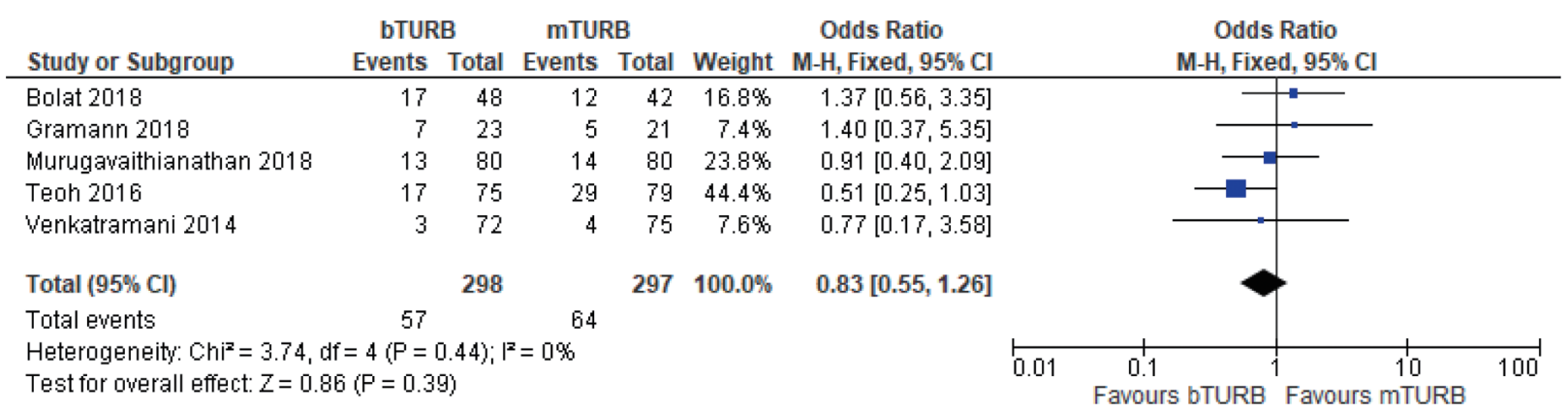

Figure 6 Forest plot and meta-analysis of failures in detrusor muscle detection. bTURB, bipolar transurethral resection of bladder tumour; mTURB, monopolar transurethral resection of bladder tumour; 95\% CI, 95\% confidence interval; M-H, Mantel-Haenszel method.

used up to present since its emergence, even though the bipolar energy is increasingly used nowadays. However, because of the fact that in the monopolar resection electric current runs from the resection loop through the patient's body to the grounding pad placed on the patient's skin, there is a risk of obturator nerve stimulation and an abrupt adductor muscles contraction. This increases significantly the risk of clinically relevant perforations $(5,25)$. What is more, as mTURB is performed in nonconductive irrigative solution (water, glycine, sorbitol, mannitol), the vascular absorption of this fluid may cause the life-threatening electrolyte disbalance. Finally, because of high resection temperatures applied with mTURB, significant collateral and penetrative tissue injury together with charring of the specimen tissues occurs $(25,26)$. Later, bipolar resection was invented to overcome abovementioned flaws of mTURB. In this technology, electric current runs between two electrodes incorporated in the resectoscope, and isotonic saline is used as the irrigant. What is more, plasma field of highly ionized particles produced around the resection tool disrupts the organic molecular bonds between tissues at relatively low temperatures $\left(40-70{ }^{\circ} \mathrm{C}\right)$. In result, bipolar resection is hypothesized to be safer and to create less thermal damages on both resection bed and histopathological samples $(6,7)$.

After performing individual calculations for analysed perioperative factors it was demonstrated that operative and hospitalization times were significantly shorter in bTURB group. On the other hand, catheterization time and decrease in postoperative $\mathrm{Hb}$ level did not differ statistically between the resection methods. Analysis revealed a significant heterogeneity in studies reporting hospitalization time and catheterization time Also, the sensitivity analysis revealed that the impact of two papers $(14,16)$ was essential in hospitalization time analysis. After omitting any of those studies statistical significance was lost. This probably might be caused by the fact, that studies were conducted in different healthcare economic systems with variable procedures coverage criteria. There was also high heterogeneity in studies reporting $\mathrm{Hb}$ decrease. This may be explained by the fact that $\mathrm{Hb}$ concentration (both before and after the procedure) is not strictly and unambiguously related to the procedure, but depends on multiple factors including (among others) patient characteristics, comorbidities and drugs, anaesthesiologic 
protocol employed, amount of intravenous fluids etc.

When complications were assessed, neither obturator nerve reflex rate, bladder perforation rate, nor transfusion rate did differ statistically. Yet, when one study (21) was omitted in obturator nerve reflex analysis, the difference achieved statistical significance. However, it has to be remembered that there is no objective method of obturator reflex reporting, and operator subjectivity may significantly influence the results. We did not assess the TUR syndrome risk, as the number of publications reporting this complication and the number of the events was minimal and therefore not suitable for statistical analysis.

Finally, 1 year recurrence rate and rate of failures in lamina muscularis detection in the histopathological specimen differences did not reach statistical significance. We could not compare the damage level of histopathological specimens due to various measurements and various definitions used across the studies.

After performing assessment of possible bias it was shown that one study had overall low risk of bias, 6 studies had a moderate and 2 studies had high overall risk of bias. However some details that are not clearly included in RoB 2 protocol should be disclosed. The populations analysed in this paper were not utterly comparable, which is caused by different studies' hypotheses and aims. As some studies included specific patients population $(13,15,16,18)$, it can limit the generalizability of presented results, even though sensitivity analysis did not show their impact on pooled analysis.

Up to date, two different meta-analyses comparing both methods were performed. In the meta-analysis from 2016, Zhao et al. showed similarly that the bTURB was associated with shorter operative time and shorter hospital stay On contrary, they demonstrated less blood loss, and shorter catheterization time. What is more, there were fewer complications such as obturator reflex and bladder perforation in the bTURB group and the recurrence rates during 2 years after the procedure were slightly more favourable (27). However, the meta-analysis included four papers from China National Knowledge Infrastructure which are not available in international databases and therefore could not be incorporated in our analysis. What is more, authors included non-randomized trials and papers evaluating tumour vaporisation.

In the next meta-analysis, presented by Cui et al. authors found that alike in our analysis, there were no statistically significant differences between bTURB and mTURB in terms of obturator reflex, bladder perforation, and transfusion rates. Also, operation time was shorter for bTURB and catheterization time did not differ statistically. Finally, the grade of tissue samples cautery artefacts and recurrence rate did not differ statistically (28). It has to be highlighted that Cui's paper is burdened with similar flows as previous meta-analysis. Additionally, authors included many case control studies and cohort studies, which, together with low number of cases and events, significantly reduces the statistical value of calculations.

\section{Conclusions}

This meta-analysis corroborates, that bTURB has an advantage over mTURB in terms of some perioperative outcomes, such as operation and hospitalization time, while other outcomes are comparable.

\section{Acknowledgments}

Funding: None.

\section{Footnote}

Reporting Checklist: The authors have completed the PRISMA reporting checklist. Available at http://dx.doi. org/10.21037/tau-20-749

Peer Review File: Available at http://dx.doi.org/10.21037/ tau-20-749

Conflicts of Interest: All authors have completed the ICMJE uniform disclosure form (available at http://dx.doi. org/10.21037/tau-20-749). The authors have no conflicts of interest to declare.

Ethical Statement: The authors are accountable for all aspects of the work in ensuring that questions related to the accuracy or integrity of any part of the work are appropriately investigated and resolved.

Open Access Statement: This is an Open Access article distributed in accordance with the Creative Commons Attribution-NonCommercial-NoDerivs 4.0 International License (CC BY-NC-ND 4.0), which permits the noncommercial replication and distribution of the article with the strict proviso that no changes or edits are made and the original work is properly cited (including links to both the formal publication through the relevant DOI and the license). 
See: https://creativecommons.org/licenses/by-nc-nd/4.0/.

\section{References}

1. Antoni S, Ferlay J, Soerjomataram I, et al. Bladder cancer incidence and mortality: a global overview and recent trends. Eur Urol 2017;71:96-108.

2. Babjuk M, Burger M, Comperat EM, et al. European Association of Urology Guidelines on Non-muscleinvasive Bladder Cancer (TaT1 and Carcinoma In Situ) 2019 Update. Eur Urol 2019;76:639-57.

3. Schraml J, Silva JDC, Babjuk M. Current concept of transurethral resection of bladder cancer: from retransurethral resection of bladder cancer to en-bloc resection. Curr Opin Urol 2018;28:591-7.

4. Zainfeld D, Daneshmand S. Transurethral resection of bladder tumors: improving quality through new techniques and technologies. Curr Urol Rep 2017;18:34.

5. Panagoda PI, Vasdev N, Gowrie-Mohan S. Avoiding the Obturator Jerk during TURBT. Curr Urol 2018;12:1-5.

6. Puppo P, Bertolotto F, Introini C, et al. Bipolar transurethral resection in saline (TURis): outcome and complication rates after the first 1000 cases. J Endourol 2009;23:1145-9.

7. Michielsen DP, Coomans D, Braeckman JG, et al. Bipolar transurethral resection in saline: the solution to avoid hyponatraemia and transurethral resection syndrome. Scand J Urol Nephrol 2010;44:228-35.

8. Moher D, Liberati A, Tetzlaff J, et al. Preferred reporting items for systematic reviews and meta-analyses: the PRISMA Statement. Open Med 2009;3:e123-30.

9. Phillips B, Ball C, Sackett D. Oxford Centre for EvidenceBased Medicine: Levels of Evidence (March 2009). Centre for Evidence-Based Medicine. 2009. Available online: https://www.cebm.ox.ac.uk/resources/levels-of-evidence/ oxford-centre-for-evidence-based-medicine-levels-ofevidence-march-2009

10. Sterne JAC, Savovic J, Page MJ, et al. RoB 2: a revised tool for assessing risk of bias in randomised trials. BMJ 2019;366:14898.

11. Harbord R, Harris R, Sterne J. Updated tests for smallstudy effects in meta-analyses. Stata J 2009;9:197-210.

12. Wan X, Wang W, Liu J, et al. Estimating the sample mean and standard deviation from the sample size, median, range and/or interquartile range. BMC Med Res Methodol 2014;14:135.

13. Bolat D, Gunlusoy B, Aydogdu O, et al. Comparing the short - term outcomes and complications of monopolar and bipolar transurethral resection of bladder tumors in patients with coronary artery disese: a prospective, randomized, controlled study. Int Braz J Urol 2018;44:717-25.

14. Del Rosso A, Pace G, Masciovecchio S, et al. Plasmakinetic bipolar versus monopolar transurethral resection of nonmuscle invasive bladder cancer: a single center randomized controlled trial. Int J Urol 2013;20:399-403.

15. Gramann T, Schwab C, Zumstein V, et al. Transurethral resection of bladder cancer on the lateral bladder wall without obturator nerve block: extent of adductor spasms using the monopolar versus bipolar technique-a prospective randomised study. World J Urol 2018;36:1085-91.

16. Hashad MM, Abdeldaeim HM, Moussa A, et al. Bipolar vs monopolar resection of bladder tumours of $>3 \mathrm{~cm}$ in patients maintained on low-dose aspirin: A randomised clinical trial. Arab J Urol 2017;15:223-7.

17. Liem EIML, McCormack M, Chan ESY, et al. Monopolar vs. bipolar transurethral resection for non-muscle invasive bladder carcinoma: A post-hoc analysis from a randomized controlled trial. Urol Oncol 2018;36:338.e1-11.

18. Mahmoud MA, Tawfick A, Mostafa DE, et al. Can bipolar energy serve as an alternative to monopolar energy in the management of large bladder tumours $>3 \mathrm{~cm}$ ? A prospective randomised study. Arab J Urol 2019;17:125-31.

19. Murugavaithianathan P, Devana SK, Mavuduru R, et al. Bipolar Transurethral Resection of Bladder Tumor Provides Better Tissue for Histopathology But Has No Superior Efficacy and Safety: A Randomized Controlled Trial. J Endourol 2018;32:1125-30.

20. Teoh JY, Chan ES, Yip SY, et al. Comparison of Detrusor Muscle Sampling Rate in Monopolar and Bipolar Transurethral Resection of Bladder Tumor: A Randomized Trial. Ann Surg Oncol 2017;24:1428-34.

21. Venkatramani V, Panda A, Manojkumar R, et al. Monopolar versus bipolar transurethral resection of bladder tumors: a single center, parallel arm, randomized, controlled trial. J Urol 2014;191:1703-7.

22. Mariappan P, Smith G, Lamb AD, et al. Pattern of recurrence changes in noninvasive bladder tumors observed during 2 decades. J Urol 2007;177:867-75.

23. Larsson $\mathrm{P}$, Wijkström H, Thorstenson A, et al. A population-based study of 538 patients with newly detected urinary bladder neoplasms followed during 5 years. Scand J Urol Nephrol 2003;37:195-201.

24. Moschini M, Roghmann F, Xylinas E. The need to improve TURB: a diagnostic and therapeutic fundamental first step in the disease's management. Transl Androl Urol 2019;8:2-4. 
25. De Nunzio C, Franco G, Cindolo L, et al. Transuretral resection of the bladder (TURB): analysis of complications using a modified Clavien system in an Italian real life cohort. Eur J Surg Oncol 2014;40:90-5.

26. Osman Y, Harraz AM. A Review comparing experience and results with bipolar versus monopolar resection for treatment of bladder tumors. Curr Urol Rep 2016;17:21.

Cite this article as: Krajewski W, Nowak $€$, Moschini M, Mari A, Di Trapani E, Xylinas E, Tukiendorf A, Poletajew S, Zdrojowy R; on behalf of Young Academic Urologists (YAU), Urothelial Cancer Party. Systematic review and meta-analysis on bipolar versus monopolar transurethral resection of bladder tumors. Transl Androl Urol 2021;10(1):37-48. doi: 10.21037/tau20-749
27. Zhao C, Tang K, Yang H, et al. Bipolar versus monopolar transurethral resection of nonmuscle-invasive bladder cancer: a meta-analysis. J Endourol 2016;30:5-12.

28. Cui Y, Chen H, Liu L, et al. Comparing the efficiency and safety of bipolar and monopolar transurethral resection for non-muscle invasive bladder tumors: a systematic review and meta-analysis. J Laparoendosc Adv Surg Tech A 2016;26:196-202. 